\title{
Prototype Sistem Pendiagnosa Penyakit dan Hama Tanaman Bawang Merah di Kabupaten Brebes dengan Metode Fuzzy Tsukamoto
}

\author{
Asih Rohmani ${ }^{1}$, Dede Untung ${ }^{2}$ \\ Fakultas Ilmu Komputer, Universitas Dian Nuswantoro \\ Jl Imam Bonjol 207 Semarang \\ e-mail: ${ }^{1}$ aseharsoyo@dsn.dinus.ac.id, ${ }^{2} 112201405205 @$ mhs.dinus.ac.id \\ Diterima: 18 April 2020; Direvisi: 8 Mei 2020; Disetujui: 9 Mei 2020
}

\begin{abstract}
Abstrak
Bawang merah merupakan komoditi andalan bagi masyrakat di wilayah Kabupaten Brebes, dimana mayoritas penduduknya adalah petani bawang merah. Didalam proses pembudidayaan tanaman bawang merah sering ditemui permasalahan yang menyebabkan turunnya hasil panen bahkan tidak jarang mengalami gagal panen. Hal ini disebabkan oleh beberapa faktor seperti cuaca, hama, dan penyakit. Banyak petani yang meresahkan kerusakan pada bawang merah yang mereka tanam akibat terkena serangan hama dan penyakit. Kurangnya pengetahuan dalam mengidentifikasi jenis hama dan penyakit yang menyerang menjadi masalah utama karena kurangnya sosialisasi yang dilakukan oleh dinas terkait dan tidak adanya media untuk melakukan konsultasi dengan pakar. Perlu sistem yang dapat menyelesaikan permasalahan tersebut. Data yang diperlukan dalam pembangunan sistem ini didapatkan dengan cara observasi, wawancara, dan studi literatur. Algoritma yang diterapkan yakni logika fuzzy metode tsukamoto. Metode yang digunakan dalam pengembangan sistem menggunakan ESDLC. Aplikasi sistem pendiagnosa penyakit hama tanaman ini dapat membantu petani untuk melakukan proses diagnosa 11 jenis hama dan penyakit yang menyerang bawang merah serta dapat dijadikan sebagai media dalam melakukan konsultasi.
\end{abstract}

Kata kunci: hama tanaman, sistem pendiagnosa, bawang merah, fuzzy tsukamoto

\begin{abstract}
Shallots are a mainstay commodity for the community in the Brebes Regency region, where the majority of the population are onion farmers. In the process of cultivating shallots plants are often encountered problems that cause a decrease in crop yields and even not infrequently experience crop failure. This is caused by several factors such as weather, pests, and diseases. Many farmers worry about the damage to the onions they plant due to pest and disease attacks. Lack of knowledge in identifying the types of pests and diseases that attack is the main problem due to the lack of socialization carried out by related agencies and the lack of media to consult with experts. Need a system that can solve these problems. Data needed in the construction of this system was obtained by observation, interviews, and literature studies. The algorithm applied is the Tsukamoto method's fuzzy logic. The method used in system development uses ESDLC. The application of the plant pest diagnosis system can help farmers to diagnose 11 types of pests and diseases that attack shallots and can be used as a medium for consultation.
\end{abstract}

Keywords: plant pests, diagnostic system, onion, tsukamoto fuzzy 


\section{PENDAHULUAN}

Kabupaten Brebes adalah satu diantara beberapa wilayah penghasil tanaman bawang merah terbesar di Indonesia. Sebanyak $70 \%$ penduduknya merupakan petani bawang merah. Dari 17 Kecamatan yang terdapat di wilayah Kabupaten Brebes, 12 Kecamatan diantaranya merupakan petani bawang merah dengan luas panen 23.000-29.000 ha dari tahun 2012-2017. Luasnya area panen selalu mengalami perubahan setiap tahunnya, dan poduk yang dihasilkan mengalami fluktuasi pada rentang waktu 5 tahun terakhir dengan rata-rata produksi $3.103 .848 \mathrm{kwintal}$ [1].

Hal tersebut disebabkan oleh berbagai macam permasalahan, diantaranya adalah adanya ancaman hama dan penyakit yang biasa menyerang bawang merah. Sebagian besar petani bawang merah disana hanyalah orang biasa yang tidak begitu familiar dengan teknologi informasi (baca:internet), sehingga pengetahuan akan cara penanganan ataupun pencegahan penyakit tanaman bawang merah ini sangat minim. Dinas Pertanian dan Ketahanan Pangan (DPKP) Kabupaten Brebes sebagai Lembaga yang menaungi para petani ini, sebenarnya sudah melaksanakan beberapa kali sosialisasi berkaitan dengan cara penanggulangan hama penyakit tanaman dan pencegahannya. Akan tetapi hal ini masih kurang efektif, dikarenakan keterbatasan jumlah personil ahli dibidang terkait dan media penyampaian informasinya. Para petani ini membutuhkan pendampingan yang lebih intens lagi, karena hama penyakit yang menyerang tanaman bawang merah ini jenisnya bermacam-macam, dengan gejala yang beragam pula. Hama penyakit juga bisa datang tiba-tiba, dan sekali terkena hama ini, maka akan menular pada tanaman lain sehingga luas area yang terkena penyakit bisa sangat lebar. Hal ini tentu saja akan mengurangi luasan area panen.

Dibutuhkan seorang petugas khusus yang selalu siap sebagai pendamping para petani di masa tanam bawang merah, untuk membantu mengendalikan hama penyakit tersebut, sehingga diharapkan luasan area panen bisa optimal. Petugas khusus di bidang penanggulangan penyakit tanaman bawang merah ini, di kabupaten Brebes hanya ada 1 orang, yang tentu saja tidak mampu untuk mengcover semua kegiatan konsultasi ataupun penyuluhan di seluruh wilayah kabupaten. Oleh karena itu dibutuhkan sebuah system yang bisa mendampingi ataupun mewakili keberadaan beliau bagi para petani ini.

Sehubungan dengan masalah ini, K.E. Winarno [2] pernah melakukan penelitian dengan objek yang sama yakni mendiagnosa hama dan penyakit pada bawang merah menggunakan metode Certainty Factor. Pada penelitiannya, jenis hama dan penyakit dikategorikan dalam 3 jenis hama dan 4 jenis penyakit, disertai dengan gejala dan hal yang menyebabkanya, serta nilai kepastian dari hama dan penyakit yang diderita. Penelitiannya menghasilkan informasi yang bisa dijadikan sebagai alternatif dalam melakukan konsultasi mengenai hama dan jenis penyakit pada tanaman bawang merah. Hasil diagnosa dari sistem pakar tersebut sesuai dengan diagnosa pakar. Y.R. Widyanto [3], menerapkan metode Fuzzy Inference Tsukamoto untuk membuat system pakar, dengan menggunakan rata-rata terbobot yang dapat membantu dalam menyelesaikan permasalahan penyakit dan hama pada tanaman jagung, berdasarkan gejala dan bobot per gejala. Hasilnya, system ini dapat mendiagnosis penyakit dengan akurasi yang tepat. Studi kasus dilakukan pada Dinas Pertanian Kota Blitar.

David McAllister dalam tulisan Z.Herdianto [4] mendefinisikan metode certainty factor sebagai suatu metode yang digunakan untuk menemukan kebenaran dari sebuah fakta yang memiliki bentuk metric apakah pasti atau tidak pasti. Akan tetapi, perdebatan yang terjadi dikalangan para ahli terkait pemodelan ketidakpastian dengan memakai angka metode certainty factor, belum menemui titik terang. Selain itu certainty factor terbatas hanya dapat mengolah 2 bobot dalam sekali perhitungan. Berbeda dengan metode certainty factor, logika fuzzy lebih mudah dimengerti dan mampu memodelkan fungsi non linear yang kompleks. Dalam metode Tsukamoto untuk aturan yang digunakan menerapkan himpunan-himpunan fuzzy yang memiliki fungsi keanggotaan konstan. Fuzzy Tsukamoto memiliki toleransi pada data dan sangat fleksibel. Kelebihannya antara lain bersifat intuitif dan dapat memberikan tanggapan berdasarkan informasi yang bersifat tak terhitung, non akurasi, dan mengambang [5]. 


\section{METODE PENELITIAN}

Pada logika fuzzy tsukamoto, setiap konsekuen dalam suatu rule yang bentuknya IFTHEN, wajib direpresentasikan menggunakan kumpulan fuzzy yang memiliki fungsi keanggotaannya konstan. Output yang dihasilkan oleh inferensi, setiap rule ditampilkan dengan tegas yang memiliki dasar $\alpha$ predikat. Untuk mendapatkan hasilnya menggunakan rata -rata terbobot. Langkah-langkah dalam fuzzy tsukamoto :

a. Fuzzyfikasi, melakukan pengubahan masukan dengan nilai tegas kedalam variable linguistik dengan memakai fungsi keanggotaan yang tersimpan didalam dasar keilmuan fuzzy.

b. Pembentukan dasar pengetahuan (rule dalam bentuk IF...THEN), yaitu secara umum bentuk model Fuzzy Tsukamoto adalah IF ( $\mathrm{X}$ is $\mathrm{A}$ ) and ( $\mathrm{Y}$ is $\mathrm{B})$ and ( $\mathrm{Z}$ is $\mathrm{C})$, dimana A,B, dan $\mathrm{C}$ adalah himpunan fuzzy.

c. Mesin Inferensi, yaitu proses dengan menggunakan fungsi implikasi MIN untuk mendapatkan nilai $\alpha$-predikat tiap-tiap rule $\left(\alpha_{1}, \alpha_{2}, \alpha_{3}, \ldots \alpha\right)$. Kemudian masing-masing nilai $\alpha$-predikat ini digunakan untuk menghitung keluaran hasil inferensi secara tegas (crisp) masing-masing rule $\left(\mathrm{z}_{1}, \mathrm{z}_{2}, \mathrm{z}_{3}, \ldots \mathrm{z}_{\mathrm{n}}\right)$.

d. Defuzzyfikasi, mengubah keluaran fuzzy yang diperoleh dari mesin inferensi menjadi nilai tegas atau crisp yang diperoleh dengan menggunakan metode rata-rata (Average) seperti pada persamaan (1) [6].

$$
Z=\frac{\sum a 1 . Z 1}{\sum a 1}
$$

Metode yang digunakan untuk membangun dan mengembangkan sistem pendiagnosa ini adalah Expert System Development Life Cycle (ESDLC). Konsep dari ESDLC ini sama dengan System Development Life Cycle (SDLC) akan tetapi, ESDLC lebih menitik beratkan pada perancangan sistem pakar.

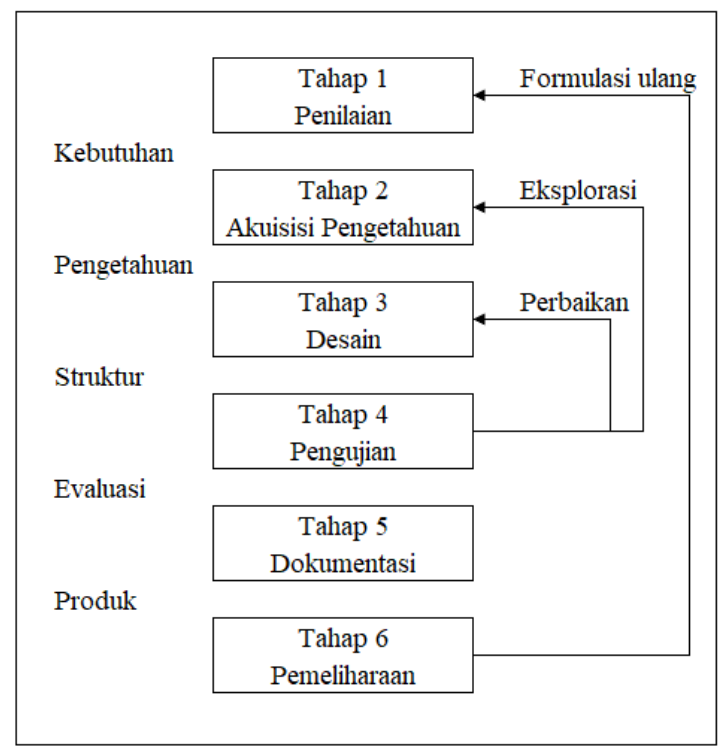

Gambar 1. Tahapan ESDLC

Seperti diilustrasikan pada gambar 1, maka tahapan ESDLC yang dilalui adalah [7] :

a) Assessment; merupakan suatu proses dalam menentukan kesesuaian terhadap sebuah masalah yang akan dibahas. Setelah proyek pengembangan dinyatakan pantas dan sesuai dengan tujuan, kemudian berikutnya menentukan fitur-fitur penting dan ruang lingkup proyek serta sumber daya yang diperlukan. Knowledge yang dibutuhkan dilakukan proses identifikasi dan menentukan syarat project pengembangan. 
b) Knowledge Acquisition; adalah proses yang dilakukan untuk memperoleh suatu knowledge mengenai masalah yang akan diangkat dan dijadikan sebagai panduan untuk mengembangkanya. Knowledge tersebut dipakai untuk sharing informasi terkait permasalahan yang menjadi referensi dalam mengembangkan desain expert system. Tahap ini melakukan proses akuisisi pengetahuan yang didapatkan dari seorang ahli terkait dari masalah yang akan dibahas.

c) Design ; pada tahap ini mulai membuat interface dan metode untuk menyelesaikan permasalahan yang kemudian diaplikasikan ke dalam expert system. Semua pengelolaan pengetahuan dilakukan proses penetapan agar dapat diimplementasikan ke dalam expert system.

d) Testing ; proses pengujian diperlukan untuk dapat melihat sejauh mana sistem pakar berjalan, apakah tujuan yang diinginkan dalam pembangunan sistem telah tercapai dan sesuai dengan metode yang digunakan berdasarkan pengetahuan yang telah didapatkan sebelumnya. Jika dalam aplikasi terdapat bagian yang tidak sesuai maka dilakukan evaluasi untuk memodifikasi bagian tersebut agar sistem dapat berjalan sesuai dengan tujuan pembangunannya.

e) Documentation; dokumentasi dilakukan atas semua informasi terkait system, yang terdiri dari cara pengoperasian sistem, kamus data, prosedur instalasi, kebutuhan minimal sistem ataupun bantuan yang diperlukan oleh user maupun developer.

f) Maintenance ; pemeliharaan sangat diperlukan, karena dengan bertambahnya waktu, maka pengetahuan juga akan semakin berkembang, sehingga pemeliharaan sistem yang dilakukan secara berkala sangat berperan untuk menyesuaikan system dengan kebutuhan.

\section{HASIL DAN PEMBAHASAN}

Langkah pertama untuk membangun sistem pendiagnosa ini adalah melakukan penilaian terhadap permasalahan yang dihadapi petani bawang merah yang ada di wilayah kabupaten Brebes. Permasalahan yang terjadi adalah minimnya pengetahuan para petani bawang merah, sementara media untuk mendapatkan informasi sangat sempit, karena keterbatasan jumlah petugas ahli penyakit dan hama tanaman bawang merah yang dimiliki oleh DPKP Kabupaten Brebes. Sebagai usulan solusi, maka diperlukan sebuah system yang bisa digunakan sebagai pendamping maupun pengganti kehadiran petugas ahli tersebut. System ini bisa diinstall di tiap Kecamatan, sehingga apabila ada petani yang membutuhkan konsultasi, mereka tidak kesulitan berkaitan dengan jarak dan waktu konsultasi. Hanya dibutuhkan seorang operator untuk membantu para petani berkonsultasi.

Tabel 1. Data penyakit tanaman bawang merah

\begin{tabular}{cl}
\hline Kode & \multicolumn{1}{c}{ Penyakit } \\
\hline P01 & Ulat Grayak \\
P02 & Hama Bodas \\
P03 & Lalat Penggorok Daun \\
P04 & Orong-orong (Anjing Tanah) \\
P05 & Tungau \\
P06 & Ngengat Gudang \\
P07 & Bercak Ungu \\
P08 & Antraknose \\
P09 & Embun Bulu \\
P10 & Layu Fusarium (Moler) \\
P11 & Nglumpruk (Leumpeuh) \\
\hline
\end{tabular}


Akuisisi pengetahuan dilakukan dengan mengolah data yang diperoleh dari petugas ahli penyakit tanaman bawang merah yang setiap gari berkantor di DPKP Kabupaten Brebes, untuk memperoleh knowledge mengenai penyakit dan hama yang menyerang tanaman bawang merah berdasarkan gejala dan menemukan solusi penanganannya. Data yang perlukan yaitu data penyakit, data gejala dan data solusi penanggulanganya. Tabel 1 menunjukkan jenis-jenis penyakit tanaman bawang merah.

Sedangkan jenis-jenis gejala yang biasa terjadi sebagai tanda-tanda bahwa tanaman bawang merah tersebut terkena penyakit, dijelaskan pada table 2 berikut.

Tabel 2. Data gejala penyakit yang menyerang tanaman bawang merah

\begin{tabular}{|c|c|}
\hline KODE & GEJALA \\
\hline G01 & Terdapat bercak putih memanjang menjadi seperti membran dan layu pada daun. \\
\hline G02 & Daun terlihat tembus cahaya atau ada bercak putih transparan dan daunnya terkulai. \\
\hline G03 & $\begin{array}{l}\text { Ada bercak mengkilap pada daun dan luka bekas gigitan yang berbentuk bintik-bintik } \\
\text { berwarna putih, lalu berubah menjadi abu-abu perak dan mengering. }\end{array}$ \\
\hline G04 & $\begin{array}{l}\text { Terjadi serangan hewan yang dimulai dari ujung-ujung daun yang masih muda, dimana } \\
\text { perkembangan dan penyebaran hama ini cepat sekali. }\end{array}$ \\
\hline G05 & $\begin{array}{l}\text { Hampir seluruh helai daun penuh dengan korokan sehingga menjadi kering dan berwarna } \\
\text { coklat seperti terbakar. }\end{array}$ \\
\hline G06 & Terdapat larva penggorok pada umbi. \\
\hline G07 & $\begin{array}{l}\text { Terdapat hewan yang tinggal di bawah permukaan tanah, menyerupai jangkrik dengan } \\
\text { panjang sekitar } 3 \mathrm{~cm} \text { dan berwarna merah tua. }\end{array}$ \\
\hline G08 & $\begin{array}{l}\text { Terdapat terowongan tanah yang berbentuk horizontal dan lebih dekat dengan } \\
\text { permukaan tanah. }\end{array}$ \\
\hline G09 & Dari kejauhan, daun terlihat abu-abu. \\
\hline G10 & Umbi keropos. \\
\hline G11 & Ada larva atau kotorannya pada umbi. \\
\hline G12 & $\begin{array}{l}\text { Terdapat bercak dengan ukuran kecil, melekuk ke dalam, berwarna putih dengan pusat } \\
\text { yang berwarna ungu (kelabu) pada daun. }\end{array}$ \\
\hline G13 & $\begin{array}{l}\text { Jika cuaca lembab, bercak berkembang hingga menyerupai cincin dengan bagian tengah } \\
\text { yang berwarna ungu dengan tepi yang kemerahan dikelilingi warna kuning yang dapat } \\
\text { meluas ke bagian atas maupun bawah bercak. }\end{array}$ \\
\hline G14 & Ujung daun membusuk dan mengering sehingga menjadi patah. \\
\hline G15 & $\begin{array}{l}\text { Umbi membusuk dan berair yang dimulai dari bagian leher kemudian mengering dan } \\
\text { berwarna lebih gelap. }\end{array}$ \\
\hline G16 & $\begin{array}{l}\text { Terdapat noda putih pada daun kemudian membentuk lekukan kedalam, berlubang dan } \\
\text { patah karena terkulai tepat pada noda. }\end{array}$ \\
\hline G17 & Pada hamparan tanaman terlihat gejala botak-botak pada beberapa tempat. \\
\hline G18 & $\begin{array}{l}\text { Pada saat tanaman mulai membentuk umbi lapis, didekat ujung daun timbul bercak hijau } \\
\text { pucat. }\end{array}$ \\
\hline G19 & Terdapat daun yang mati berwarna putih diliputi oleh kapang hitam. \\
\hline G20 & $\begin{array}{l}\text { Pada waktu cuaca lembab pada permukaan daun berkembang kapang (mould jamur) } \\
\text { yang berwarna putih lembayung atau ungu. }\end{array}$ \\
\hline G21 & Umbi membusuk sehingga lama-kelamaan tanaman mati. \\
\hline G22 & $\begin{array}{l}\text { Tanaman cepat layu, akar tanaman busuk, tanaman terkulai seperti akan roboh, dan di } \\
\text { dasar umbi lapis terlihat koloni jamur berwarna putih. }\end{array}$ \\
\hline G23 & $\begin{array}{l}\text { Daun bawang merah menguning dan terpelintir layu serta mudah tercabut karena } \\
\text { pertumbuhan akar terganggu dan membusuk. }\end{array}$ \\
\hline G24 & $\begin{array}{l}\text { Noda berwarna putih kekuningan tumbuh dengan cepat sesuai dengan arah bertiupnya } \\
\text { angin di awal pertanaman. }\end{array}$ \\
\hline
\end{tabular}

Sedangkan cara-cara pengendalian hamanya, dijelaskan pada table 3 berikut: 
Tabel 3. Data cara pengendalian hama penyakit tanaman bawang merah

\begin{tabular}{|c|c|}
\hline $\begin{array}{c}\text { KODE } \\
\text { PENYA } \\
\text { KIT }\end{array}$ & CARA PENGENDALIAN \\
\hline P01 & $\begin{array}{l}\text { - Mengumpulkan telur dan ulat bawang lalu dimasukkan dalam kantong plastik dan diikat, } \\
\text { terutama pada saat bawang merah berumur 7-35 hari, lalu dimusnahkan. } \\
\text { - Memasang lampu perangkap mulai dari seminggu sebelum tanam sampai menjelang panen }( \pm 60 \\
\text { hari), dari pukul } 18.00-06.00 \text {. Ketinggian lampu } 10-15 \mathrm{~cm} \text { dari permukaan tempat air s.d. pucuk } \\
\text { tanaman, sedangkan mulut bak harus kurang dari } 40 \mathrm{~cm} \text { diatas pucuk tanaman. Jarak antar lampu } \\
20 \mathrm{~m} \times 15 \mathrm{~m} \text {. } \\
\text { - Pemasangan perangkap feromonoid seks dipasang sebanyak } 40 \text { buah/ha untuk menangkap } \\
\text { ngengat } S \text {. Exigua setelah bawang merah ditanam. }\end{array}$ \\
\hline
\end{tabular}

P02 - Memangkas bagian daun yang terserang.

- Penggunaan insektisida fosfor organic yang mengandung bahan aktif kuinalfos, kemudian Mesurol 50 WP yang mengandung bahan aktif merkaptodimetur, ataupun Azodrin 15 WSC dan Nuvacron 20 SCW yang mengandung bahan aktif monokotofos

P03 - Pergiliran tanaman; jika diketahui ada serangan lalat L. chinensis, sebaiknya satu musim berikutnya tidak menanam tanaman bawang.

- Penggunaan mulsa plastik berwarna perak yang dipasang sebelum tanam, lalu diberi lubang disetiap titik jarak tanam dengan garis tengah lubang yang cukup untuk berkembangnya tanaman bawang merah sampai panen akan mematikan larva yang jatuh dari daun.

- Daun yang menunjukkan gejala korokan dipotong dan dibutit lalu dimusnahkan.

- Pemasangan kain kelambu

- Perangkap lampu neon dengan waktu nyala mulai pukul 18.00-24.00 paling efisien dan efektif untuk menangkap imago.

P04 - Menggunakan pupuk kandang yang matang untuk mengurangi serangan Gryllotalpa sp.

- Menjaga sanitasi yang baik untuk mengurangi serangan Gryllotalpa sp.

- Pemasangan umpan beracun yang dianjurkan, yang disebar diatas bedengan pertanaman pada senja hari.

P05 - Penyemprotan dengan menggunakan akarisida yang mengandung bahan aktif fenpropatrin atau dimetoat, dimulai sejak tanaman berumur 9 minggu hingga 2 minggu sebelum panen. Ha ini dilakukan selang waktu seminggu sekali.

P06 - Menyemprotkan pestisida kedalam ruangan tertutup atau kedap udara untuk beberapa waktu dalam dosis dan konsentrasi yang dapat mematikan hama.

- Menanam bawang di lahan yang mempunyai drainase yang baik dan memberlakukan rotasi tanaman.

- Penyiraman setelah turun hujan dapat mengurangi serangan, karena penyiraman dapat mencuci konidium yang menempel pada daun bersama percikan air tanah

- Penyakit dapat juga dikendalikan dengan penyemprotan fungisida

P08 - Karena infeksi terjadi lewat umbi benih, penyakit dapat dikurangi dengan perawatan benih. Melakukan rotasi tanaman .

- Memberantas gulma yang ddapat menjadi inang untuk bertahannya patogen.

- Memperbaiki aerasi dan drainasi agar tidak ada air yang tergenang dan kelembaban pertanaman tidak terlalu tinggi. Memperlebar jarak tanam terutama pada musim penghujan (Suhendro, et al., 2000).

- Penyemprotan fungisida dapat mengurangi penyakit.

P09 - Pemakaian benih yang sehat

- Jika penyakit banyak timbul, setelah panen, daun-daun dibakar. Tanah jangan ditanami bawang selama 3 tahun. 
- Tanaman disemprot dengan fungisida. Penyemprotan dimulai 1 minggu sebelum tanaman dicabut dari pembibitan.

P10 - Melakukan pergiliran tanaman dengan tanaman yang bukan inangnya.

- Drainase dan kebersihan lingkungan dijaga sebaik mungkin.

- Pencegahan di daerah endemis Fusarium, perlu perlindungan benih dengan menaburkan fungisida yang diberikan dua atau tiga hari sebelum tanam.

- Di daerah endemis sebelum tanam, tanah yang sudah diolah diberi fungisida untuk mematikan patogen dan Fusarium.

- Menggunakan pupuk organik yang ditaburkan pada bedengan sebelum tanam.

- Menerapkan sanitasi yang baik untuk mengurangi jumlah inokulum patogen yang ada. Penyiangan gulma/rumput dilakukan rutin agar tanah tidak terlalu lembab.

- Menyiram di pagi hari agar tanaman mengering sebelum malam hari. Pengairan dengan penggenangan juga bisa dilakukan secara terukur, yakni dua hari sekali selama 15-30 menit tergantung kondisi kelembaban tanah.

- Gunakan plastik mulsa pada waktu tanam musim hujan. Plastik mulsa berfungsi untuk menjaga kelembaban tanah dan mencegah tumbuhnya gulma

- Rotasi tanaman setiap tiga atau empat kali masa panen agar tidak terjadi penumpukkan patogen. Rotasi tanaman bawang merah bisa dilakukan dengan padi.

- Segera cabut tanaman bawang merah yang terserang hama penyakit. Kemudian tumpuk dan bakar agar patogen tidak cepat menyebar ke mana-mana. Sedangkan untuk penanganan secara kimiawi, pemberian fungisida dilakukan begitu ada tanda-tanda penyakit di area penanaman. Ada jenis fungsida yang khusus untuk mengatasi penyakit stemphylium, tapi tersedia pula fungisida yang sekaligus untuk beberapa penyakit. Hanya saja aplikasinya harus terkendali agar tidak menyisakan terlalu banyak residu kimia.

\subsection{Implementasi Fuzzy Tsukamoto}

\section{A. Fuzifikasi}

Variabel yang digunakan adalah gejala dengan tingkat kerusakan, dan penyakit dengan besar serangan. Himpunan yang terdapat dalam tingkat kerusakan dibagi menjadi 4 variabel linguistik yaitu sedikit, sedang, banyak, dan sangat banyak. Sama halnya dengan tingkat kerusakan, himpunan besar serangan juga terbagi menjadi 4 variabel linguistik yaitu ringan, sedang, berat, dan sangat berat. Masing-masing himpunan telah ditentukan intervalnya dengan satuan persen (\%). Tingkat kerusakan sebanding dengan besarnya serangan. Untuk itu, pembagian intervalnya sama, seperti disajikan dalam table 4 berikut ini.

Tabel 4. Interval tingkat kerusakan dan besar serangan

\begin{tabular}{llll}
\hline Tingkat Kerusakan & Interval $(\%)$ & Besar Serangan & Interval $(\%)$ \\
\hline Sedikit & $0-30 \%$ & Ringan & $0-30 \%$ \\
Sedang & $20-55 \%$ & Sedang & $20-55 \%$ \\
Banyak & $45-80 \%$ & Berat & $45-80 \%$ \\
Sangat Banyak & $70-100 \%$ & Sangat Berat & $70-100 \%$ \\
\hline
\end{tabular}

Fungsi keanggotaan logika Fuzzy digunakan untuk menghitung derajat keanggotaan suatu himpunan fuzzy. Fungsi keanggotaan adalah kurva yang menunjukkan pemetaan titik input data kedalam nilai keanggotaannya. Ada beberapa fungsi keanggotaan, persamaan (2) menunjukkan representasi linear naik, dimana kenaikan himpunan dimulai dari nilai domain yang memiliki derajat keanggotaan nol bergerak kekanan menuju nilai domain yang memiliki nilai derajat keanggotaan lebih tinggi. Sedangkan persamaan (3) menunjukkan sebaliknya, yaitu fungsi linear turun, dimulai dari derajat keanggotaan tertinggi bergerak menurun menuju derajat keanggotaan yang lebih rendah. Persamaan (4) adalah fungsi keanggotaan dimana ada beberapa titik yang memiliki nilai keanggotaan 1 . 


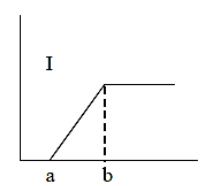

$$
\mathrm{I}(\mathrm{x} ; \mathrm{a}, \mathrm{b})=\left\{\begin{aligned}
0, & x \leq a \\
\frac{x-a}{b-a}, & a \leq x \leq b \\
1, & x \geq b
\end{aligned}\right.
$$

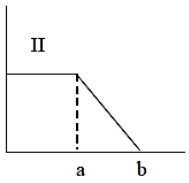

$\mathrm{II}(\mathrm{x} ; \mathrm{a}, \mathrm{b})=\left\{\begin{array}{cc}0, & x \geq b \\ \frac{b-x}{b-a}, & a \leq x \leq b \\ 1, & x \leq a\end{array}\right.$

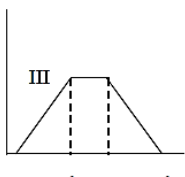

$\mathrm{III}(\mathrm{x} ; \mathrm{a}, \mathrm{b}, \mathrm{c}, \mathrm{d})=\left\{\begin{array}{cl}\frac{x-a}{b-a}, & x \leq a \\ 1, & b \leq x \leq c \\ \frac{d-x}{d-c}, & c \leq x \leq d \\ 0, & x \geq d\end{array}\right.$

Gambar 2 menunjukkan kurva fungsi keanggotaan tingkat kerusakan.

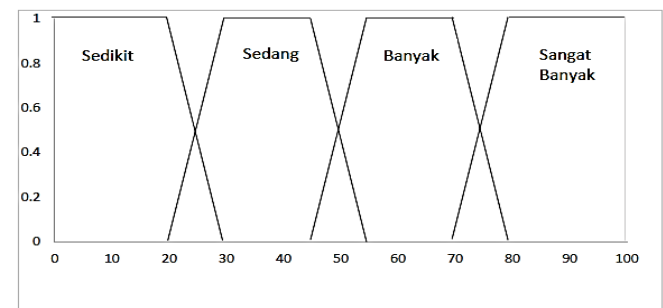

Gambar 2 . Kurva fungsi keanggotaan tingkat kerusakan

Sesuai dengan ketentuan interval kerusakan pada table 4, maka persamaan (5) merupakan hasil perhitungan fungsi keanggotaan tingkat kerusakan sedikit. Sedangkan persamaan (6) merupakan fungsi keanggotaan untuk tingkat kerusakan sedang, persamaan (7) untuk tingkat kerusakan banyak dan persamaan (8) adalah fungsi keanggotaan untuk tingkat kerusakan sangat banyak.

$$
\begin{gathered}
\mu \text { Sedikit }=\left\{\begin{aligned}
0, & x \geq 30 \\
\frac{30-x}{30-20,}, & 20 \leq x \leq 30 \\
1, & x \leq 20
\end{aligned}\right. \\
\mu \text { Sedang }=\left\{\begin{aligned}
\frac{x-20}{30-20,}, & x \leq 20 \leq x \leq 30 \\
1, & 30 \leq x \leq 45 \\
\frac{55-x}{55-45}, & 45 \leq x \leq 55 \\
0, & x \geq 55
\end{aligned}\right.
\end{gathered}
$$

$$
\begin{aligned}
& \mu \text { Banyak }=\left\{\begin{array}{cl}
0, & x \leq 45 \\
\frac{x-45}{55-45}, & 45 \leq x \leq 55 \\
1, & 55 \leq x \leq 70 \\
\frac{80-x}{80-70}, & 70 \leq x \leq 80 \\
0, & x \geq 80
\end{array}\right. \\
& \mu \text { Sangat Banyak }=\left\{\begin{aligned}
0, & x \leq 70 \\
\frac{x-70}{80-70}, & 70 \leq x \leq 80 \\
1, & x \geq 80
\end{aligned}\right.
\end{aligned}
$$

Sedangkan untuk kurva fungsi keanggotaan besar serangan, divisualisasikan pada gambar 3 sebagai berikut :

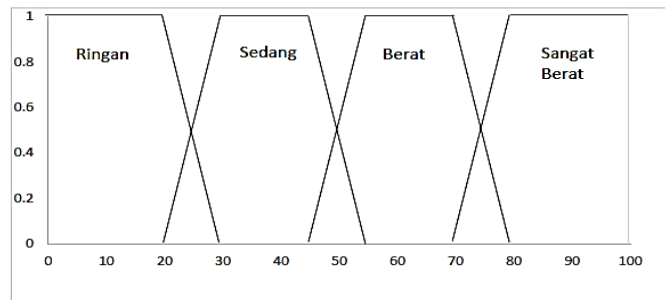

Gambar 3. Kurva fungsi keanggotaan besar serangan 
Fungsi keanggotaan besar serangan dihitung berdasarkan interval yang sudah ditentukan pada table 4. Persamaan (9) menunjukkan fungsi keanggotaan besar serangan dalam kategori ringan, persamaan (10) menunjukkan fungsi keanggotaan besar serangan dalam kategori sedang, persamaan (11) menunjukkan fungsi keanggotaan besar serangan dalam kategori berat dan persamaan (12) menunjukkan fungsi keanggotaan besar serangan dalam kategori sangat berat.

$$
\begin{gathered}
\mu \text { Ringan }=\left\{\begin{aligned}
0, & z \geq 30 \\
\frac{30-z}{30-20,}, & 20 \leq z \leq 30 \\
1, & z \leq 20
\end{aligned}\right. \\
\mu \text { Sedang }=\left\{\begin{aligned}
\frac{0,20}{30-20,} & 20 \leq z \leq 30 \\
1, & 30 \leq z \leq 45 \\
\frac{55-z}{55-45}, & 45 \leq z \leq 55 \\
0, & z \geq 55
\end{aligned}\right.
\end{gathered}
$$

$$
\begin{gathered}
\mu \text { Berat }=\left\{\begin{aligned}
0, & z \leq 45 \\
\frac{z-45}{55-45}, & 45 \leq z \leq 55 \\
1, & 55 \leq z \leq 70 \\
\frac{80-z}{80-70}, & 70 \leq z \leq 80 \\
0, & z \geq 80
\end{aligned}\right. \\
\mu \text { Sangat Berat }=\left\{\begin{aligned}
0, & z \leq 70 \\
\frac{z-70}{80-70,}, & 70 \leq z \leq 80 \\
1, & z \geq 80
\end{aligned}\right.
\end{gathered}
$$

\section{B. Pembentukan Rule}

Proses pembentukan rule bertujuan untuk menarik kesimpulan jenis hama dan penyakit serta besar serangan yang sesuai dengan inputan gejala dan tingkat serangan yang telah diinputkan oleh pengguna dengan membentuk aturan-aturan yang didapatkan dari seorang ahli bawang merah. Ada 417 aturan yang terbentuk dalam penelitian. Berikut sampel dari rule yang terbentuk:

[R1] IF G01 Sedikit AND G02 Sedikit THEN P01 Ringan

[R2] IF G01 Sedikit AND G02 Sedang THEN P01 Sedang

[R3] IF G01 Sedikit AND G02 Banyak THEN P01 Berat

[R4] IF G01 Sedikit AND G02 Sangat Banyak THEN P01 Sangat Berat

$\cdots$

$\cdots$

[R417] IF G23 Sangat Banyak AND G24 Sangat Banyak THEN P11 Sangat Berat

\section{Mesin Inferensi}

Proses selanjutnya adalah menentukan nilai $\alpha$-predikat dari setiap rule yang terpicu, kemudian nilai tersebut digunakan untuk menghitung keluaran inferensi secara tegas (crisp) dari masing-masing rule. Misalnya ditemukan permasalahan yang memiliki gejala penyakit "Terdapat bercak putih memanjang menjadi seperti membran dan layu pada daun" dengan tingkat kerusakan $22 \%$ dan gejala penyakit "Daun terlihat tembus cahaya atau ada bercak putih transparan dan daunnya terkulai" dengan tingkat kerusakan sebesar $24 \%$. Dari contoh permasalahan tersebut, maka langkah pertama yang perlu dilakukan adalah menentukan fungsi keanggotaan variable. Persamaan (13) menunjukkan hasil perhitungan fungsi keanggotaan untuk kasus diatas.

$$
\begin{aligned}
& \mu G 01 \text { Sedikit }(22)=\frac{30-22}{30-20}=0,8 \quad \mu G 02 \text { Sedikit }(24)=\frac{30-24}{30-20}=0,6 \\
& \mu G 01 \text { Sedang }(22)=\frac{22-20}{30-20}=0,2 \quad \mu G 02 \text { Sedang }(24)=\frac{24-20}{30-20}=0,4
\end{aligned}
$$

Setelah fungsi keanggotaan ditemukan, langkah berikutnya adalah mengaplikasikanya kedalam aturan-aturan yang dipicu sehingga akan diperoleh $\alpha$-predikat dan nilai z dengan mengaplikasikan fungsi implikasi MIN: 
[R1] IF G01 Sedikit AND G02 Sedikit THEN P01 Ringan

$\alpha 1 \quad=\min (\mu \mathrm{G} 01$ Sedikit(22); $\mu \mathrm{G} 02$ Sedikit(24))

$=\min (0,8 ; 0,6)$

$\alpha 1 \quad=0,6$

$\mu$ P01 Ringan $=\frac{30-\mathrm{z}}{30-20}$

$0,6=\frac{30-\mathrm{z}}{10}$

$30-\mathrm{z}=6$

$\mathrm{z} 1 \quad=24$

[R2] IF G01 Sedikit AND G02 Sedang THEN P01 Sedang

$\alpha 2=\min (\mu \mathrm{G} 01$ Sedikit(22); $\mu \mathrm{G} 02$ Sedang(24))

$=\min (0,8 ; 0,4)$

$\alpha 2=0,4$

$\mu \mathrm{P} 01$ Sedang $=\frac{\mathrm{z}-20}{30-20}$ $\mu \mathrm{P} 01$ Sedang $=\frac{55-\mathrm{z}}{55-45}$

$0,4=\frac{\mathrm{z}-20}{10}$

$0,4=\frac{55-\mathrm{z}}{10}$

$z-20=4$

$55-\mathrm{z}=4$

$\mathrm{z} 2=24$

$\mathrm{z} 2=51$

$\mathrm{z} 2=\min (24 ; 51)=24$

\section{[R5] IF G01 Sedang AND G02 Sedikit THEN P01 Ringan}

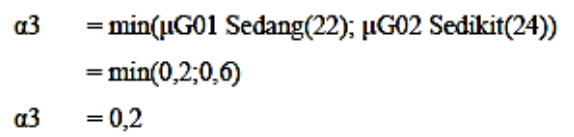

$\mu \mathrm{P} 01$ Ringan $=\frac{30-\mathrm{z}}{30-20}$

$0,2=\frac{30-\mathrm{z}}{10}$

$30-z=2$

$\mathrm{z3}=28$

[R6] IF G01 Sedang AND G02 Sedang THEN P01 Sedang

$\alpha 4=\min (\mu \mathrm{G} 01$ Sedang(22); $\mu \mathrm{G} 02$ Sedang(24))

$=\min (0,2 ; 0,4)$

$\alpha 4 \quad=0,2$

$\mu \mathrm{P} 01$ Sedang $=\frac{\mathrm{z}-20}{30-20}$

$\mu \mathrm{P} 01$ Sedang $=\frac{55-\mathrm{z}}{55-45}$

$0,2=\frac{z-20}{10}$

$0,2=\frac{55-\mathrm{z}}{10}$

$\mathrm{z}-20=2$

$55-\mathrm{z}=2$

$\mathrm{z} 4 \quad=22$

$\mathrm{z} 4 \quad=53$

$\mathrm{z} 4=\min (22 ; 53)=22$

D. Defuzyfikasi

Keluaran fuzzy yang dihasilkan dari mesin inferensi berdasarkan aturan yang telah ditentukan kemudian diubah menjadi nilai $\mathrm{Z}$ dengan menggunakan metode perhitungan rata-rata pada persamaan : 


$$
\begin{aligned}
& Z=\frac{\alpha 1 \times \mathrm{z} 1+\alpha 2 \times \mathrm{z} 2+\alpha 3 \times \mathrm{z} 3+\alpha 4 \times \mathrm{z} 4}{\alpha 1+\alpha 2+\alpha 3+\alpha 4} \\
& Z=\frac{0,6 \times 24+0,4 \times 24+0,2 \times 28+0,2 \times 22}{0,6+0,4+0,2+0,2} \\
& Z=\frac{14,4+9,6+5,6+4,4}{1,4} \\
& Z=24,286
\end{aligned}
$$

Nilai yang dihasilkan dari proses perhitungan defuzyfikasi adalah 24,286. Berdasarkan hasil dari proses perhitungan fuzzy tsukamoto dengan gejala penyakit "Terdapat bercak putih memanjang menjadi seperti membran dan layu pada daun" dengan tingkat kerusakan $22 \%$ dan gejala penyakit "Daun bawang terlihat menerawang tembus cahaya atau terlihat bercak putih transparan dan daunya terkulai" dengan tingkat kerusakan sebesar $24 \%$ tersebut menderita serangan hama ulat grayak dengan tingkat serangan $24,286 \%$.

E. Desain

Proses desain sistem dalam penelitian ini menggunakan bahasa Unified Modeling Language (UML) yang merupakan bahasa standar dalam pendokumentasian dan pembangunan perangkat lunak yang berbasis object oriented. UML adalah metode pemodelan dan perancangan sistem secara visual. Gambar 4 dan 5 adalah rancangan use case diagram yang menggambarkan interaksi antara petugas ahli selaku admin dan user (petani dan masyarakat) dengan sistem. Admin dapat melakukan beberapa aktivitas untuk mengelola system baik melakukan perubahan maupun menghapus konten didalam sistem.

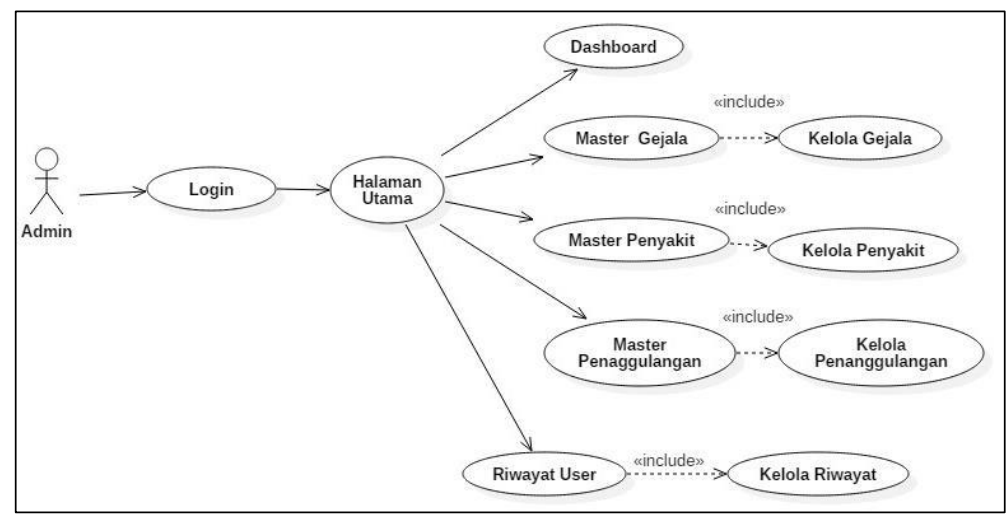

Gambar 4. Use diagram admin

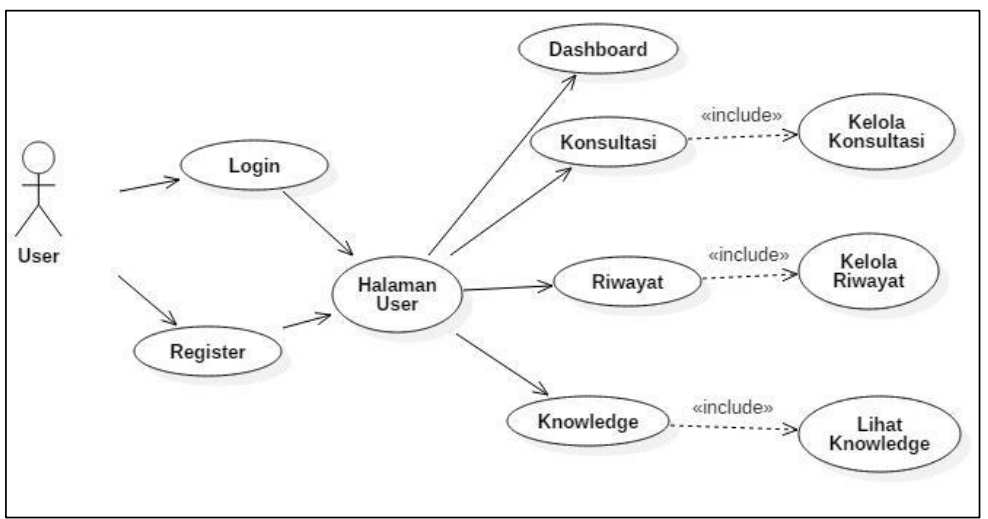

Gambar 5. Use case diagram user 
Dari use case tersebut, maka class diagram system, dapat digambarkan seperti pada gambar 6 berikut.

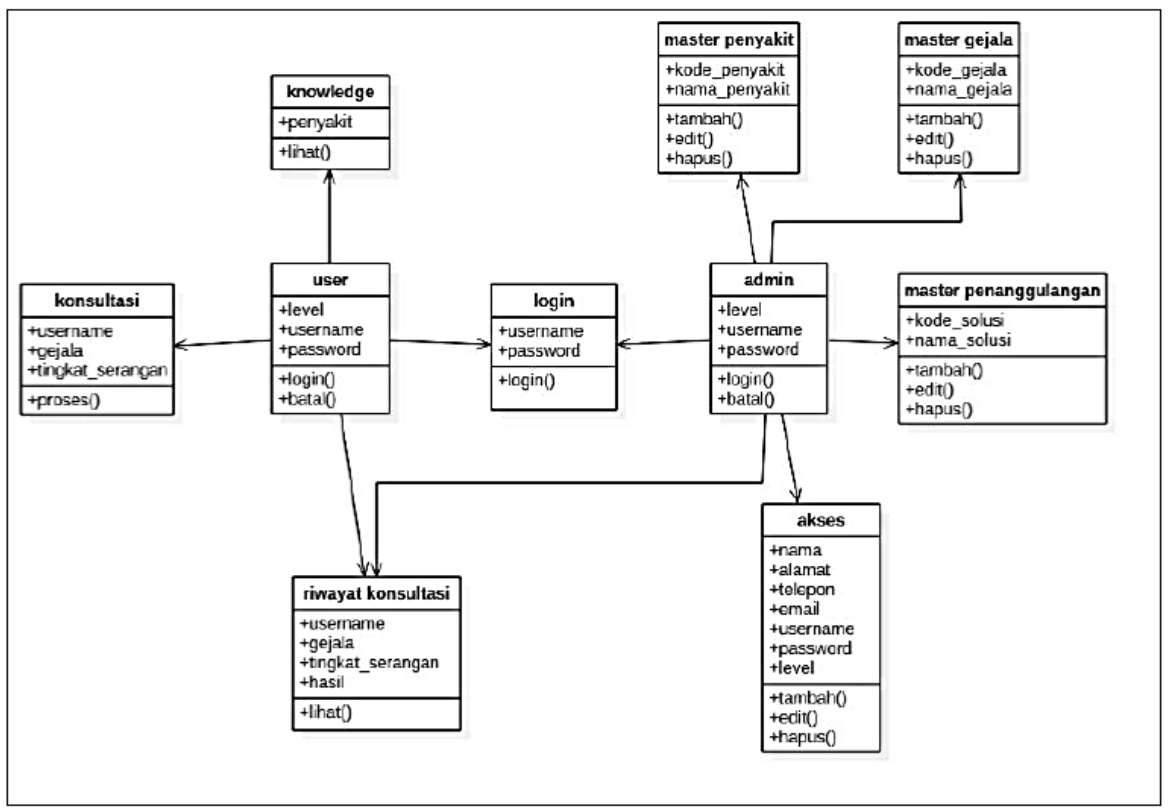

Gambar 6. Class diagram sistem pendiagnsa hama dan penyakit pada tanaman bawang merah

\section{F. Pengujian}

Proses pengujian dilakukan dengan menggunakan metode User Aceptance Testing, yakni pengujian yang ditujukan kepada pengguna dengan output berupa dokumen hasil pengujian yang menegaskan bahwa aplikasi dapat diterima dan telah memenuhi persyaratan kebutuhan[8]. Berdasarkan hasil pengujian yang dilakukan dari 22 responden dengan 7 pertanyaan terkait sistem pendiagnosa ini, dapat ditarik kesimpulan bahwa sistem pendiagnosa hama dan penyakit tersebut memiliki tampilan yang menarik, menu didalamnya mudah untuk dipahami, pengoperasian aplikasi dapat dijalankan dengan mudah, gejala-gejala yang sesuai, solusi yang diberikan oleh sistem dapat membantu menyelesaikan permasalahan. Sistem juga dapat dijadikan sebagai media konsultasi tanpa harus menemui seorang ahli/pakar, dan sistem ini dapat menambah wawasan tentang penyakit yang menyerang tanaman bawang merah.

\section{KESIMPULAN}

Berdasarkan pembahasan dan penelitian yang dilakukan, dapat ditarik kesimpulan bahwa aplikasi sistem pendiagnosa hama dan penyakit pada tanaman bawang merah yang dibangun dapat membantu untuk mendiagnosa 11 penyakit tanaman bawang merah yang ada di wilayah kabupaten Brebes. Informasi yang dihasilkan dari aplikasi tersebut yakni berupa nama penyakit beserta dengan gejala dan cara penanggulangannya, dapat membantu para petani dalam menyelesaikan permasalahan yang dihadapi, serta menambah wawasan mereka mengenai jenisjenis penyakit yang bisa menyerang tanaman mereka.

\section{SARAN}

Aplikasi ini hanya dapat digunakan untuk mendiagnosa 11 jenis hama dan penyakit yang menyerang tanaman bawang merah, untuk pengembangan lebih lanjut dapat ditambahkan lebih 
dari 11 jenis hama dan penyakit. Perangkat lunak sistem pendiagnosa hama dan penyakit pada tanaman bawang merah ini dapat dikembangkan lebih lanjut agar dapat digunakan untuk menunjang proses konsultasi yang lebih baik.

\section{DAFTAR PUSTAKA}

[1] B.P.S.K. Brebes, "Luas Panen dan Rata-Rata Produksi Bawang Merah Di Kabupaten Brebes 2012-2017," Badan Pusat Tatistik Kabupaten Brebes, 31 Desember 2018. [Online]. Available: https://brebeskab.bps.go.id/dynamictable/2018/12/31/62/luas-penen-produksidan-rata-rata-produksi-bawang-merah-di-kabupaten-brebes-2012--2017.html. [Accessed 04 Januari 2019].

[2] K.E.Winarno, "Sistem Pakar Diagnosis Penyakit Tanaman Bawang Merah Menggunakan Metode Certainty Factor Dengan Mesin Inferensy FOrward Chaining Berbasis web," Jurnal Mahasiswa Teknik Informatika, vol. III, pp. 144-151, 2019.

[3] Y.R.Widyano, "Sistem Pakar Diagnosa Penyakit Tanaman Jagung," Teknologi Informasi, 2016.

[4] Z.Herdianto, "Certainty Factor Kelompok 5," 09 November 2012. [Online]. Available: https://www.scribd.com/document/112675338/MAKALAH-KLOMPOK-5. [Accessed 16 Januari 2019].

[5] G.A.Khotaro, "Sistem Diagnosis Penyakit Antraknosa Pada Cabai Menggunakan Metode Fuzzy Tsukamoto," Pengembangan Teknologi Informasi dan Ilmu Komputer, vol. III, pp. 582-586, 2019.

[6] V.N.Kinanti, "Prototype Penyaring Asap Rokok Pada Smoking Area Menggunakan Pulse Width Modulation (PWM) Dan Fuzzy Tsukamoto," semanTIK, vol. II, pp. 195-202, 2016.

[7] C.R.M.Yusuf, "Perancangan Sistem Pakar untuk Diagnosis Penyakit Amenorea Dengan Menggunakan Metode Expert System Development Life Cycle," Jurnal Algoritma, vol. II, 2014.

[8] P.I.S.R.F. Munthe Rouli, "Usulan Metode Evaluasi User Acceptance Testing," in SENAPATI, Singaraja, 2015. 